\title{
Low Temperature Bonding of Pd/Ni Assembly for Hydrogen Purifier
}

\author{
Yan-Cheng Lin ${ }^{1}$, Chien-Hsun Chuang ${ }^{2}$, Hsing-Hua Tsai ${ }^{3}$, Tung-Han Chuang ${ }^{4}$ \\ ${ }^{1,4}$ Institute of Materials Science and Engineering, National Taiwan University, \\ No. 1, Roosevelt Rd., Sec. 4, Taipei 106, Taiwan \\ d02527013@ntu.edu.tw; tunghan@ntu.edu.tw \\ ${ }^{2,3}$ Wire Technology Co., LTD, No. 27, Aly. 56, Ln. 320, Sec. 1, Shatian Rd., Dadu Dist, Taichung 432, Taiwan \\ josh604@hotmail.com.tw; cashtsai@wiretech.com.tw
}

\begin{abstract}
For manufacturing a Pd cell for hydrogen purification, a key technology is the bonding of a Pd fine tube with a stainless steel grasp. In this study, the SLID method has been employed to join Pd sheet and Ni plate to evaluate the bendability between a Pd tube and a Ni coated stainless steel grasp. The results indicated that directly inserting a Sn interlayer with a thickness of $8.5 \mu \mathrm{m}$ between the Pd sheet and $\mathrm{Ni}$ plate caused the formation of $\mathrm{Ni}_{3} \mathrm{Sn}_{4}$ and $\mathrm{PdSn}_{4}$ intermetallic compounds, respectively. However, certain $\mathrm{Sn}$ interlayer remained after SLID bonding and low shear strength of 5.3 MPa was obtained. Furthermore, the remaining of low melting point Sn interlayer cannot withstand the operating temperature (above $350^{\circ} \mathrm{C}$ ) of SLID assembled Pd cell for hydrogen purification. Reducing the $\mathrm{Sn}$ interlayer thickness to $3 \mu \mathrm{m}$ led to the complete exhausting of Sn interlayer. Unfortunately, a long crack appeared at the $\mathrm{Ni}_{3} \mathrm{Sn}_{4} / \mathrm{PdSn}_{4}$ interface and a low bonding strength was resulted. Adding an Ag thin layer between the Sn coated Pd sheet and Ni plate caused an Ag ${ }_{3} \mathrm{Sn}$ intermetallic compound to form between the $\mathrm{Ni}_{3} \mathrm{Sn}_{4}$ and $\mathrm{PdSn}_{4}$ layers, and cracking of the Pd/Ni joint was prevented. This improvement led to satisfactory bonding strengths ranging from 10.6 to $17.3 \mathrm{MPa}$. High temperature storage at $400^{\circ} \mathrm{C}$ for $100 \mathrm{hr}$ did not degrade the bonding interfaces or bonding strengths.
\end{abstract}

Keywords: Pd cell, solid liquid interdiffusion bonding, $\mathrm{Sn} / \mathrm{Ag} / \mathrm{Sn}$ interlayers, intermetallic compounds, bonding strength, high temperature storage.

\section{Introduction}

Hydrogen with a high purity of $6 \mathrm{~N}$ to $9 \mathrm{~N}$ is required for the manufacturing of IC and LED chips. For example, the purity of hydrogen used in the MOCVD process is above $7 \mathrm{~N}$. Even the hydrogen used for fuel cells must have a high purity of $4 \mathrm{~N}$ to $6 \mathrm{~N}$. Therefore, hydrogen purification is an important technique in the IC, LED, and fuel cell industries. Palladium has good selectivity for hydrogen and stable material properties. Therefore, it is often used as the material for hydrogen purification. The principle of hydrogen purification can be described as in Fig.1: The hydrogen gas $\left(\mathrm{H}_{2}\right)$ dissociates on the surface of Pd sheet into $\mathrm{H}$ atoms, which diffuse through the Pd sheet and recombine on the other side into purified $\mathrm{H}_{2}$ gas. The other impure gases with larger atom size will be screened during this process. For the hydrogen purification, multiple Pd fine tubes are assembled with a SAE 304 stainless steel grasp as a Pd cell shown in Fig. 2. The Pd cell is then operated at a temperature above $350^{\circ} \mathrm{C}$ during the hydrogen purification process. For manufacturing a Pd assembly, a key technology is the bonding of a Pd fine tube with a stainless steel head. Because Pd fine tubes have a diameter of about $2 \mathrm{~mm}$ and a thickness of about $60 \mu \mathrm{m}$, the Pd cell can be deformed if the traditional brazing or laser welding approaches are used. In contrast, soldered Pd cell cannot endure the high operation temperature above $350^{\circ} \mathrm{C}$ for hydrogen purifier due to the lower melting point of conventional solder alloy.

Solid-Liquid Interdiffusion Bonding (SLID) is a bonding method based on the principle of isothermal solidification and interfacial intermetallics reaction. As shown in Fig. 3, this technique makes use of a low-melting metallic thin film interlayer (LT) such as Sn or In inserted between the high-melting bulk work pieces or metallic layers on certain substrates (HT1 and HT2) that are to be joined. The LT interlayer, which is molten at low temperatures, reacts rapidly with the HT1 and HT2 bulk materials or layers. After a short time of interfacial reaction, the LT interlayer is exhausted and has completely transformed into intermetallic compounds (IMCs). The melting point of the newly-formed intermetallic phases is much higher than that of the original LT interlayer, so the resulting joints can withstand considerably higher temperatures when the assembled products are operated [1]. Since solid liquid interdiffusion bonding has the merits of a low bonding temperature process and high temperature application, it has been applied in the past few decades to the manufacturing of microwave 
packages, high power devices, thick-film resistors, GaAs/Si wafer packages, and even gold jewelry. Recently, diffusion soldering has also been employed for ceramic multichip modules [2,3], MEMS packaging [4], semiconductor packaging [5], hybrid joining [6], and hermetic package sealing [7].

In our previous studies, $\mathrm{Bi}_{0.5} \mathrm{Sb}_{1.5} \mathrm{Te}_{3}$, $(\mathrm{Pb}, \mathrm{Sn}) \mathrm{Te}$, and $\mathrm{GeTe}$ thermoelectric materials were bonded with $\mathrm{Cu}$ electrodes using the SLID process with an inserted Sn interlayer [8-10]. Satisfactory joints with sufficient bonding strengths were obtained in these cases. In addition, SLID method has also been applied in the 3D-IC flip-chip packaging, which indicated that the SLID bonded joints had a higher reliability than that of traditional soldered bumps [11]. The bonding temperature during the SLID process can be further reduced through employment of an indium interlayer [12]. In this study, the SLID method has been further used to join Pd sheet and Ni plate to evaluate the bendability between a Pd tube and a Ni coated stainless steel grasp.

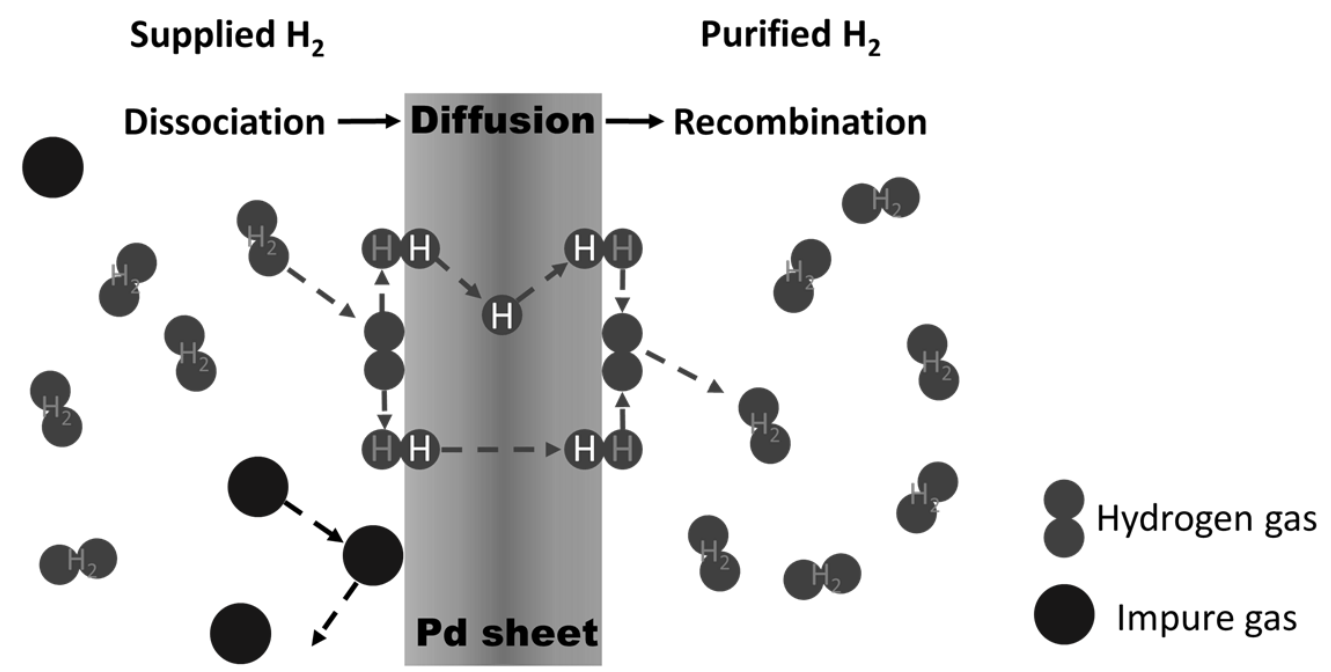

Fig. 1: The principle of hydrogen purification using a Pd sheet.

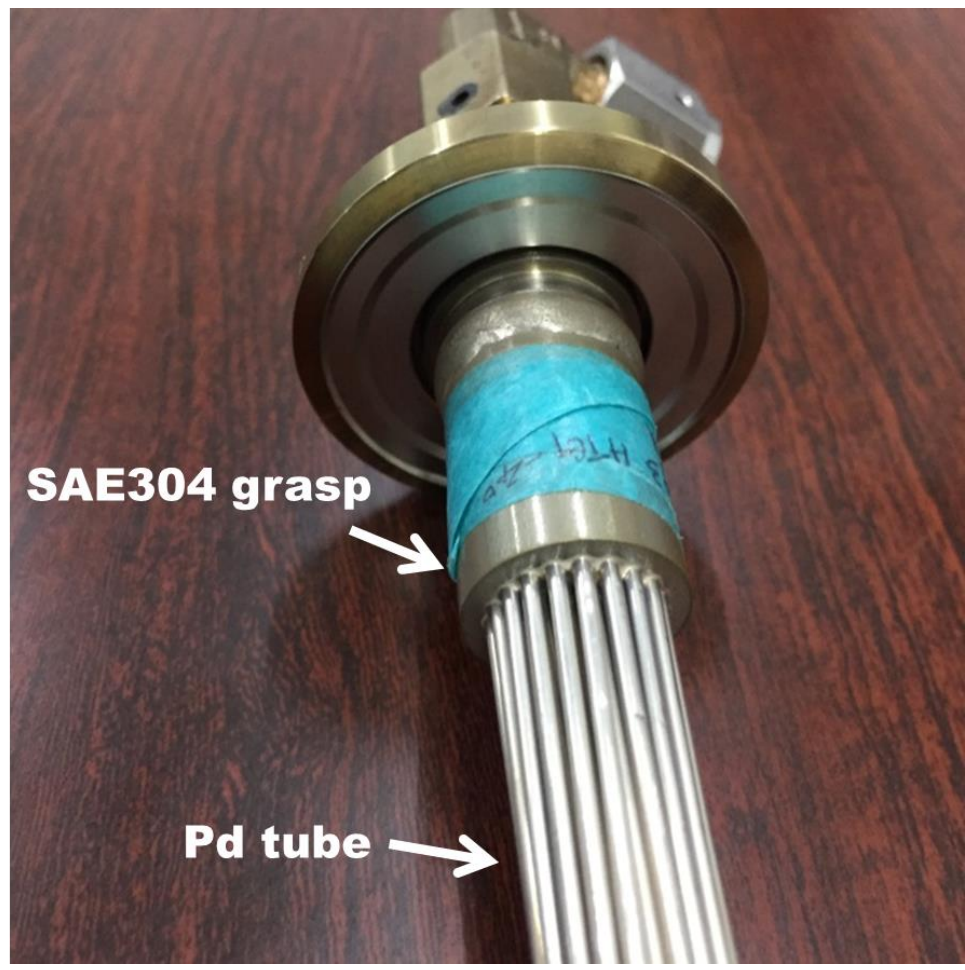

Fig. 2: Palladium cell for hydrogen purification. 

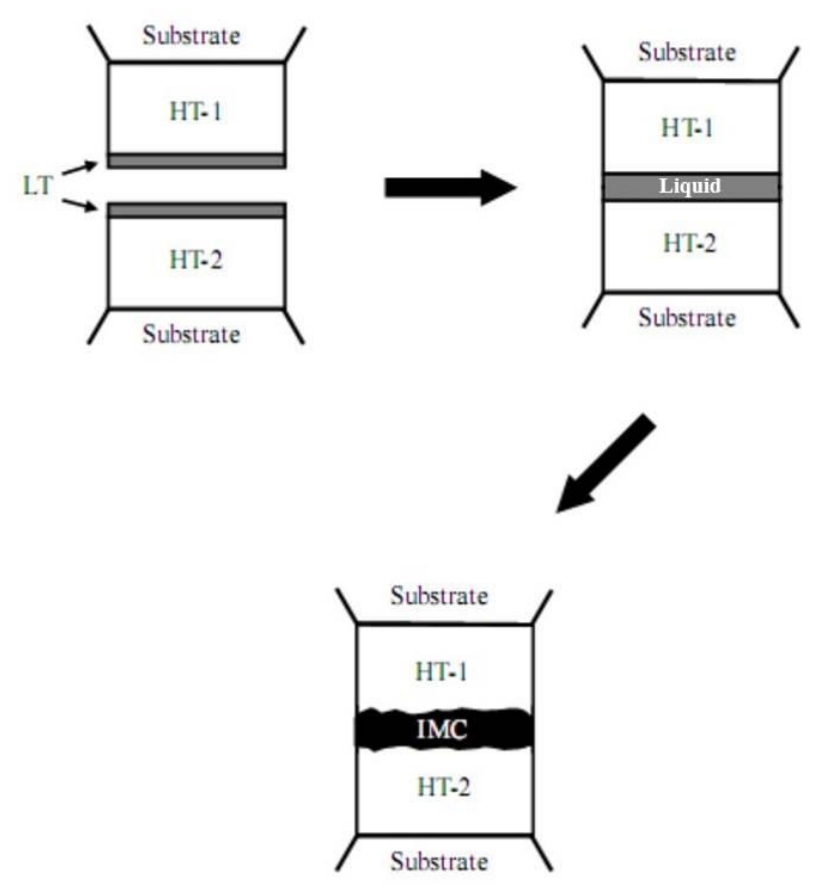

Fig. 3: Schematic representation of the principle of solid liquid interdiffusion bonding.

\section{Experimental}

A palladium sheet with a thickness of $0.1 \mathrm{~mm}$ was joined with a Ni plate with a thickness of $1 \mathrm{~mm}$ using the solidliquid interdiffusion (SLID) bonding process shown in Fig. 3. For the preparation of the bonding specimens, the Pd sheet was ground with 4,000 Grit $\mathrm{SiC}$ paper, electroplated with a Sn thin film interlayer, and then assembled with a Ni plate. The SLID bonding was conducted in a vacuum furnace of $5.3 \times 10^{-4} \mathrm{~Pa}$ and subsequently heated at various temperatures between $275^{\circ} \mathrm{C}$ and $350^{\circ} \mathrm{C}$ for $30 \mathrm{~min}$ under a pressure of $3 \mathrm{MPa}$, as shown in Fig. 4. After the bonding processes, the specimens were cross-sectioned, ground with 4,000 Grit $\mathrm{SiC}$ paper, and polished with 1 and $0.3 \mu \mathrm{m} \mathrm{Al}_{2} \mathrm{O}_{3}$ powders. The microstructures of the intermetallic compounds that formed at the interfaces were observed with scanning electron microscopy (SEM), and their chemical compositions were analyzed with energy dispersive X-ray spectroscopy (EDX). The shear strengths of various $\mathrm{Pd} / \mathrm{Ni}$ assemblies were tested with a DAGE 4000 Bond Tester at a speed of $0.3 \mathrm{~mm} / \mathrm{s}$.
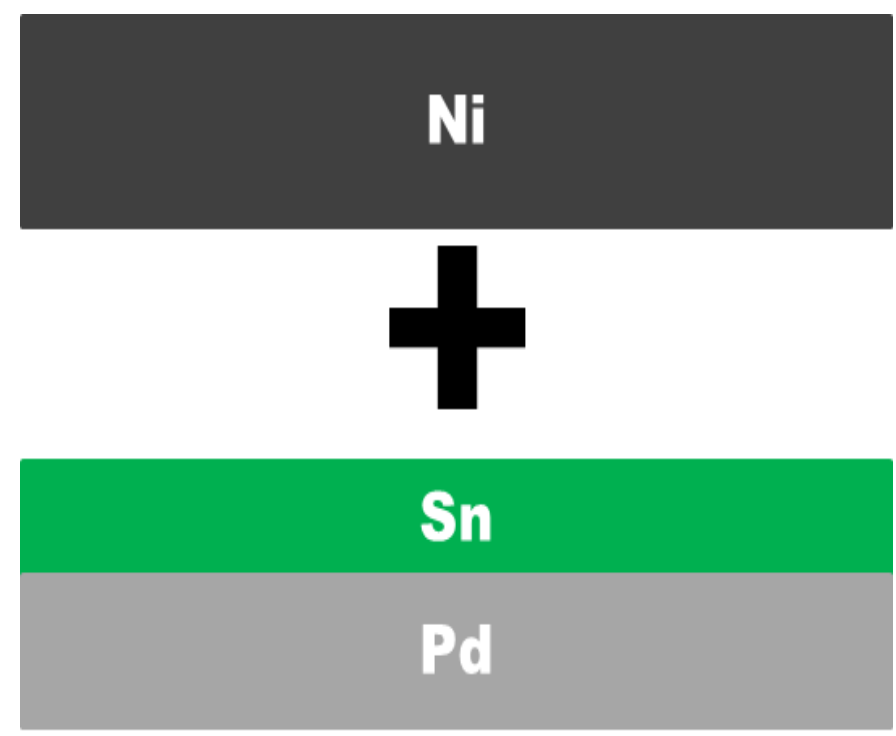

Fig. 4: Schematic representation of the SLID bonding of Pd sheet with Ni plate using a Sn interlayer. 


\section{Results and Discussion}

Figure 5 shows the microstructure of a $\mathrm{Pd} / \mathrm{Ni}$ joint with an $8.5 \mu \mathrm{m}$ thick $\mathrm{Sn}$ interlayer after SLID bonding at $300^{\circ} \mathrm{C}$ for $30 \mathrm{~min}$. It can be seen that the Pd sheet and $\mathrm{Ni}$ plate reacted with the $\mathrm{Sn}$ interlayer to form $\mathrm{PdSn}_{4}$ and $\mathrm{Ni}_{3} \mathrm{Sn}_{4}$ intermetallic compounds, respectively. In this case, some of the $\mathrm{Sn}$ interlayer remained between the $\mathrm{Ni}_{3} \mathrm{Sn}_{4}$ and $\mathrm{PdSn}_{4}$ intermetallic layers. During the shear test, the specimen fractured through the Sn interlayer, which resulted in a low bonding strength of 5.3 MPa. In addition, the remaining Sn interlayer in the Pd cell assembly would melt during the hydrogen purification process. To solve this problem, the thickness of the Sn interlayer was reduced to $3 \mu \mathrm{m}$ and SLID bonding was conducted at $300^{\circ} \mathrm{C}$ for 30 min. Figure 6 indicates that the Sn interlayer was exhausted under this condition. However, a long crack appeared between the $\mathrm{Ni}_{3} \mathrm{Sn}_{4}$ and $\mathrm{PdSn}_{4}$ intermetallic layers, and a very low bonding strength was obtained. The appearance of cracks at $\mathrm{Ni}_{3} \mathrm{Sn}_{4} / \mathrm{PdSn}{ }_{4}$ interface is similar to that reported by Bader et al. for the SLID bonding of $\mathrm{Ni} / / \mathrm{Ni}$ and $\mathrm{Cu} / / \mathrm{Cu}$ couples using Sn interlayers [13].

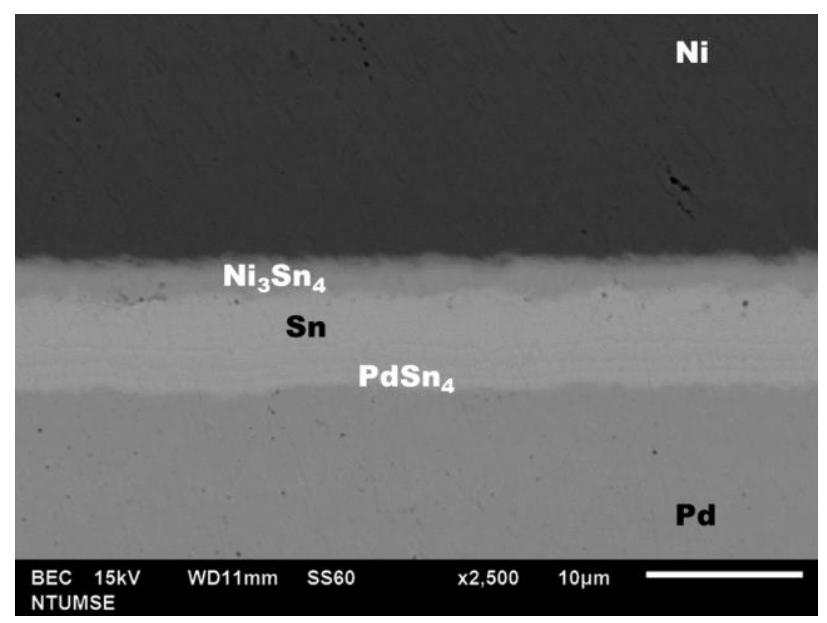

Fig. 5: Microstructure of the SLID bonded Pd/Ni couple using a Sn interlayer of $8.5 \mu \mathrm{m}$ thickness.

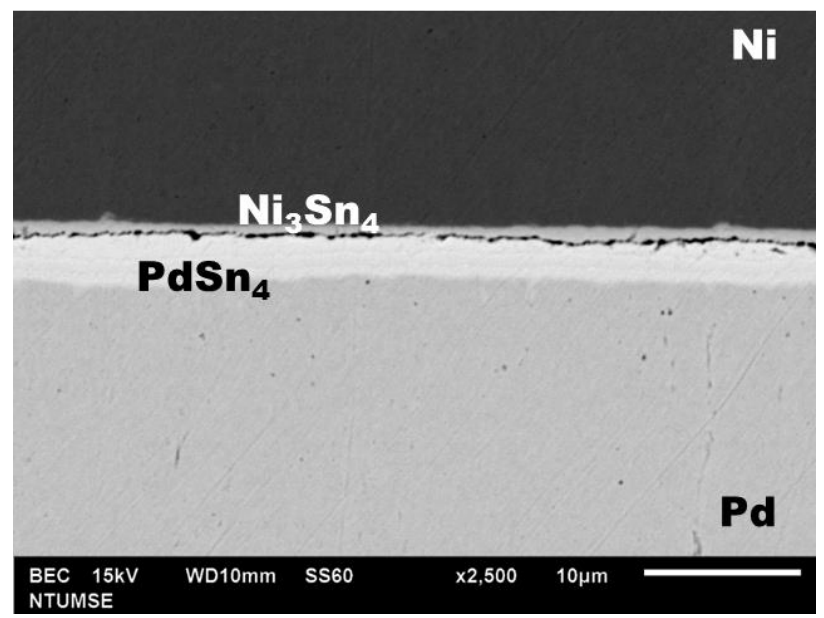

Fig. 6: Microstructure of the SLID bonded Pd/Ni couple using a $3 \mu \mathrm{m}$ thick Sn interlayer.

In our previous study, it was verified that inserting an $\mathrm{Ag}_{3} \mathrm{Sn}$ intermetallic layer between $\mathrm{Ni}-\mathrm{Sn}$ or $\mathrm{Cu}-\mathrm{Sn}$ intermetallic compounds eliminated interfacial voids [14]. The SLID bonding process was modified to include a Sn/Ag/Sn multilayer between the Pd sheet and Ni plate, as shown in Fig. 7. Figure 8 shows that this improvement prevented the cracking shown in Fig. 5, and a sound interface was achieved in the Pd/Ni joint. In addition to the formation of $\mathrm{Ni}_{3} \mathrm{Sn}_{4}$ and $\mathrm{PdSn} 4$ intermetallic compounds, a $\mathrm{Ag}_{3} \mathrm{Sn}$ intermetallic layer appeared between the $\mathrm{Ni}_{3} \mathrm{Sn}_{4}$ and $\mathrm{PdSn}_{4}$. Shear tests indicated that satisfactory bonding strengths ranging from 10.6 to $17.3 \mathrm{MPa}$ can be achieved with SLID bonding at temperatures between 270 and $325^{\circ} \mathrm{C}$ for $30 \mathrm{~min}$, as shown in Fig. 9. The shear strength of SLID- Pd/Ni joint decreased from the maximal value of 17.3 
MPa to 12.2 MPa for the increasing of bonding temperature from $325^{\circ} \mathrm{C}$ to $350^{\circ} \mathrm{C}$, which can be attributed to the high thermal stress during the SLID bonding at $350^{\circ} \mathrm{C}$. For the evaluation of reliability, the $\mathrm{Pd} / \mathrm{Ni}$ joint pre-bonded at $300^{\circ} \mathrm{C}$ for $30 \mathrm{~min}$ was aged at $400^{\circ} \mathrm{C}$ for $100 \mathrm{hr}$, which caused the $\mathrm{Ni}_{3} \mathrm{Sn}_{4}$ intermetallic layer to grow from about 1.2 to $4.7 \mu \mathrm{m}$, while the $\mathrm{Ag}_{3} \mathrm{Sn}$ and $\mathrm{PdSn}_{4}$ intermetallic layers decreased slightly as shown in Fig.10. It was also found that the bonding strengths did not decayed obviously after this high temperature storage.
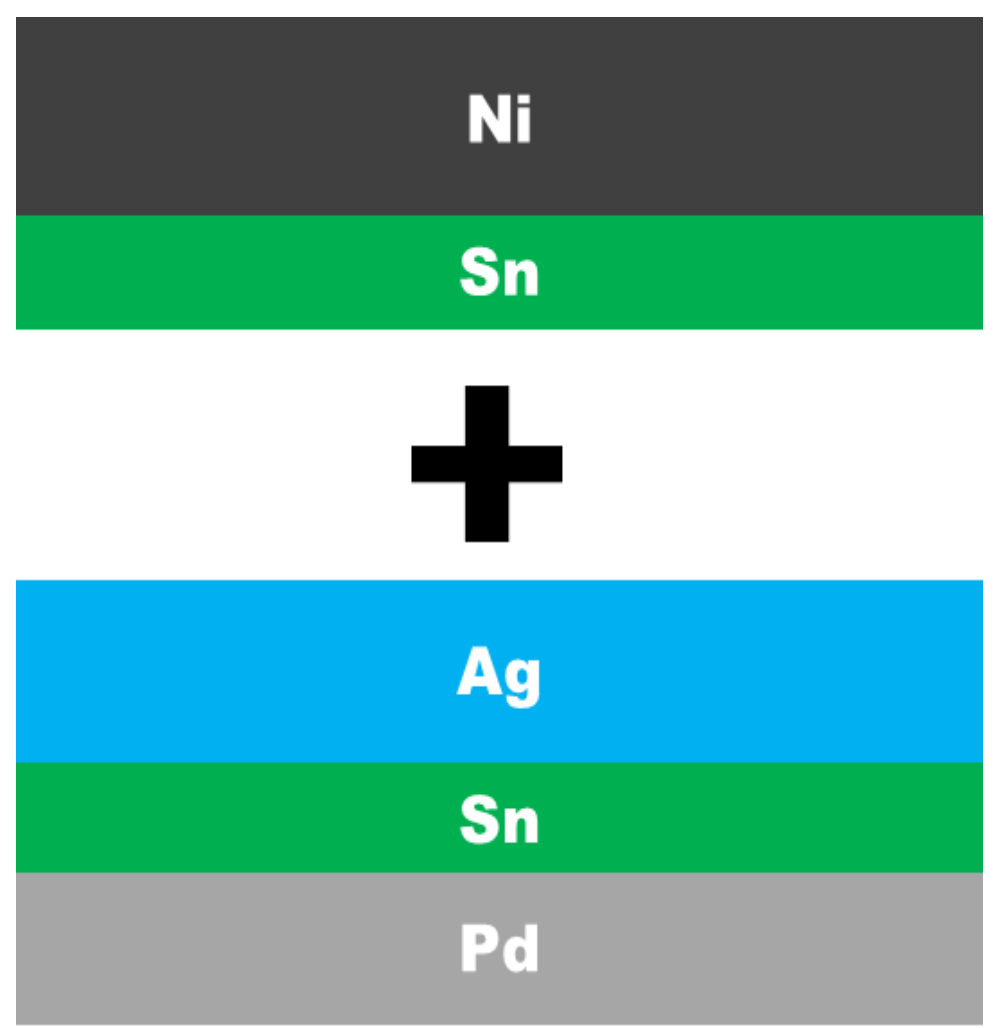

Fig. 7: Schematic presentation of the SLID bonding of Pd sheet with Ni plate using $\mathrm{Sn} / \mathrm{Ag} / \mathrm{Sn}$ interlayers.

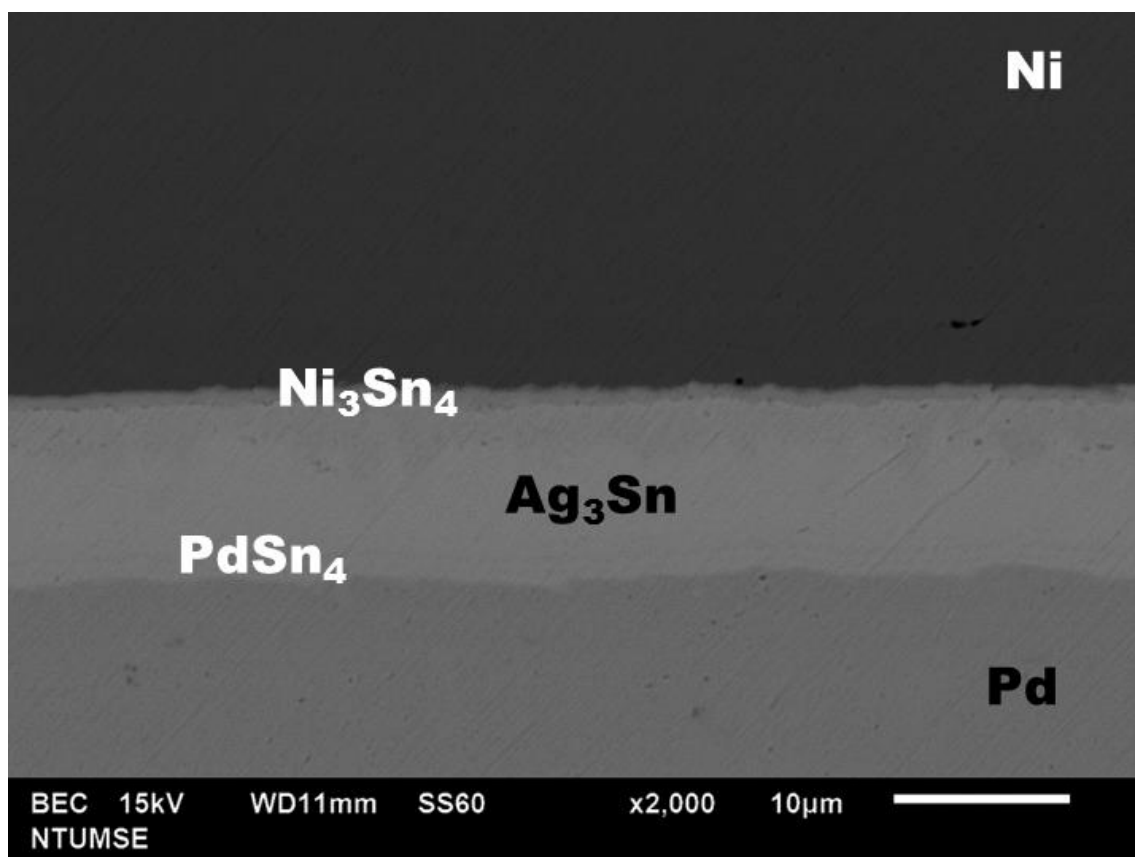

Fig. 8: Microstructure of the SLID bonded Pd/Ni couple using Sn/Ag/Sn interlayers. 
Fig. 9: Shear strengths of the SLID bonded Pd/Ni couple using $\mathrm{Sn} / \mathrm{Ag} / \mathrm{Sn}$ interlayers.

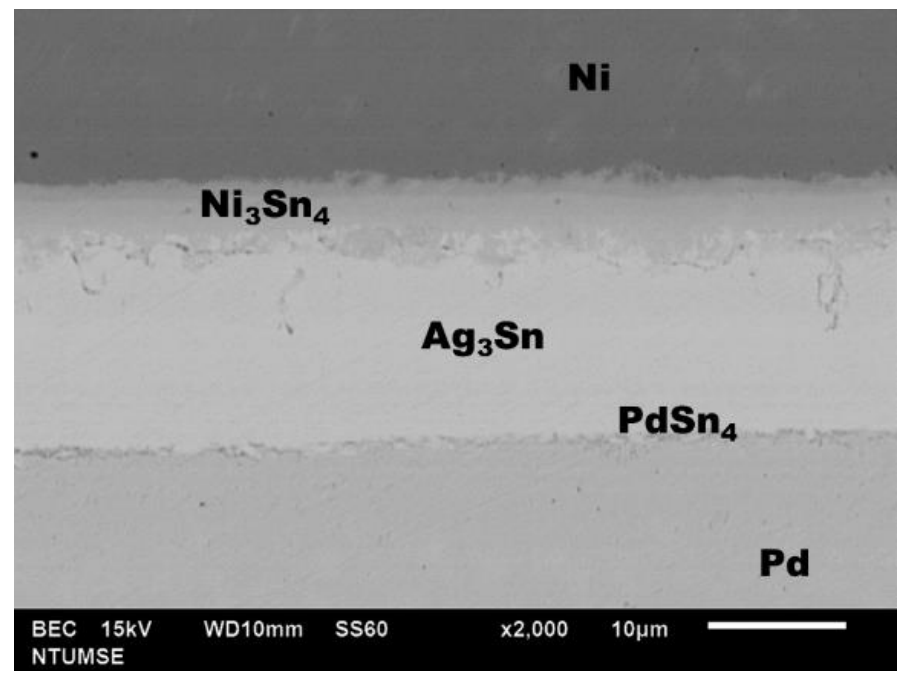

Fig. 10: Microstructure of the SLID bonded Pd/Ni couple using Sn/Ag/Sn interlayers after high temperature storage at $400^{\circ} \mathrm{C}$ for 100 hr.

\section{Conclusions}

Pd sheet and Ni plate can be bonded with the solid liquid interdiffusion bonding method. The results indicated that directly electroplating a $3 \mu \mathrm{m}$ thick Sn interlayer on the Pd sheet and SLID bonding with the Ni plate resulted in the complete exhaust of $\mathrm{Sn}$ film and the formation of $\mathrm{Ni}_{3} \mathrm{Sn}_{4}$ and $\mathrm{PdSn}_{4}$ intermetallic compounds, respectively. Unfortunately, a long crack appeared at the $\mathrm{Ni}_{3} \mathrm{Sn}_{4} / \mathrm{PdSn}_{4}$ interface, and a low bonding strength of $5.3 \mathrm{MPa}$ was obtained. Inserting an Ag layer between the $\mathrm{Sn}$ coated Pd sheet and $\mathrm{Ni}$ plate caused an additional $\mathrm{Ag}_{3} \mathrm{Sn}$ intermetallic compound to form between the $\mathrm{Ni}_{3} \mathrm{Sn}_{4}$ and $\mathrm{PdSn}_{4}$ intermetallic layers, and cracking of the $\mathrm{Pd} / \mathrm{Ni}$ joint was prevented. Satisfactory bonding strengths ranging from 10.6 to $17.3 \mathrm{MPa}$ have been achieved with SLID bonding at temperatures between 275 and $350^{\circ} \mathrm{C}$ for $30 \mathrm{~min}$ using $\mathrm{Sn} / \mathrm{Ag} / \mathrm{Sn}$ interlayers. High temperature storage at $400^{\circ} \mathrm{C}$ for $100 \mathrm{hr}$ did not degrade the bonding interface or bonding strength.

\section{Acknowledgements}

This study was sponsored by the Small Business Innovation Research (SBIR) program of the Ministry of Economic Affairs (MOEA), Taiwan, under Grant No.1Z1041847, and by the industrial and academic cooperation program of Wire Technology Co. and the Ministry of Science and Technology, Taiwan, under Grant No. MOST 103-2622-E002-012-CC2. 


\section{References}

[1] D. M. Jacobson and G. Humpston, "Diffusion soldering," Solder. Surf. Mt. Tech., vol. 10, pp. 27-32, 1992.

[2] T. H. Chuang, H. J. Lin, and C. W. Tsao, "Intermetallic compounds formed during diffusion soldering $\mathrm{Au} / \mathrm{Cu} / \mathrm{Al}_{2} \mathrm{O}_{3}$ and $\mathrm{Cu} / \mathrm{Ti} / \mathrm{Si}$ with $\mathrm{Sn} / \mathrm{In}$ interlayer," J. Electron. Mater., vol. 35, pp. 1566-1570, 2006.

[3] M. W. Liang, T. E. Hsieh, S. Y. Chang, and T. H. Chuang, "Thin-film reactions during diffusion soldering of $\mathrm{Cu} / \mathrm{Ti} / \mathrm{Si}$ and $\mathrm{Au} / \mathrm{Cu} / \mathrm{Al}_{2} \mathrm{O}_{3}$ with Sn interlayers," J. Electron. Mater., vol. 32, pp. 952-956, 2003.

[4] W. C. Welch, J. Chae, and K. Najafi, "Transfer of metal MEMS packages using a wafer-level solder transfer technique," IEEE Trans. Adv. Packag., vol. 28, pp. 643-649, 2005.

[5] R. I. Made, C. L. Gan, L. L.Yan, A. Yu, S. W. Yoon, J. H. Lau, and C. K. Lee, "Sudy of low-temperature thermocompression bonding in Ag-In solder for packaging applications," J. Electron. Mater., vol. 38, pp. 365-371, 2009.

[6] J. F. Li, P. A. Agyakwa, and C. W. Johnson, "Kinetics of Ag3Sn growth in Ag-Sn-Ag system during transient liquid phase soldering process," Acta Metall. Mater., vol. 58, pp. 3429-3443, 2010.

[7] L. L. Yan, C. K. Lee, D. Q. Yu, A. B. Yu, W. K. Choi, J. H. Lau, and S. U. Yoon, "A Hermetic Seal Using Composite Thin-Film In/Sn Solder as an Intermediate Layer and Its Interdiffusion Reaction with Cu," J. Electron. Mater., vol. 38, pp. 200-207, 2009.

[8] C. L. Yang, H. J. Lai, J. D. Hwang, and T. H. Chuang, "Diffusion soldering of $\mathrm{Bi}_{0.5} \mathrm{Sb}_{1.5} \mathrm{Te}_{3}$ thermoelectric material with Cu electrode," J. Mater. Eng. Perform., vol. 22, pp. 2029-2037, 2013.

[9] T. H. Chuang, H. J. Lin, C. H. Chuang, W. T. Yeh, J. D. Hwang, and H. S. Chu, "Solid liquid interdiffusion bonding of $(\mathrm{Pb}, \mathrm{Sn}) \mathrm{Te}$ thermoelectric modules with $\mathrm{Cu}$ electrodes using a thin-film Sn interlayer," J. Electron. Mater., vol. 43, pp. 4610-4618, 2014.

[10] C. L. Yang, H. J. Lai, J. D. Hwang, and T. H. Chuang, "Diffusion soldering of Pb-doped GeTe thermoelectric modules with Cu electrodes using a thin-film Sn interlayer," J. Electron. Mater., vol. 42, pp. 359-365, 2013.

[11] J. Y. Chang, R. S. Cheng, K. S. Kao, T. C. Chang, and T. H. Chuang, "Reliable Microjoints formed by Solid Liquid Interdiffusion (SLID) Bonding within a Chip-Stacking Architecture," IEEE Trans. Compon. Packag. Manufact. Technolog., vol. 6, pp. 979-984, 2012.

[12] T. H. Chuang, W. T. Yeh, C. H. Chuang, and J. D. Hwang, "Improvement of bonding strength of a (Pb,Sn)Te-Cu contact manufactured in a low temperature SLID-bonding process," J. Alloy Compd., vol. 613, pp. 46-54, 2014.

[13] S. Bader, W. Gust, and H. Hieber, "Rapid frometion of intermetallic compounds interdiffusion in the $\mathrm{Cu}-\mathrm{Sn}$ and Ni-Sn systems," Acta Metall. Mater., vol. 43, pp. 329-337, 1995.

[14] J. Y. Chang, T. C. Chang, T. H. Chuang, and C. Y. Lee, "Dual-Phase Intermetallic Interconnections Structure and Method of Fabricating the Same," US Patent 8,742,600 B2, Jun. 3, 2014. 